\title{
New Phase Formation in Hetero-Structured Multilayers of Tricosa-2,4-diynoic Acid and Arachidic Acid
}

\author{
Shuji OKadA, Hachiro NAKANishi, Hiro Matsuda, \\ Masao KATo, Michio Sugi, ${ }^{*}$ Mitsuyoshi SAIto,* \\ and Sigeru IIZIMA* \\ Research Institute for Polymers and Textiles, \\ 1-1-4, Higashi, Tsukuba, Ibaraki 305, Japan \\ *Electrotechnical Laboratory, 1-1-4, Umezono, \\ Tsukuba, Ibaraki 305, Japan
}

(Received December 23, 1987)

\begin{abstract}
Four different types of hetero-structured multilayers of tricosa-2,4-diynoic acid (18-0ADA) and arachidic acid $\left(\mathrm{C}_{20} \mathrm{CA}\right)$ in cadmium salts were prepared, and the structures and polymerization behavior of 18-0ADA in such hetero-multilayers were compared with those in the multilayers of pure 18-0ADA. A new phase of 18-0ADA was found in the multilayers having hydrophilic interactions with $\mathrm{C}_{20} \mathrm{CA}$, whereas in the multilayers having hydrophilic interactions by themselves new and original phases were mixed up. To clarify these phenomena, the structures of the same types of hetero-multilayers of fatty acids were also investigated, and no new phases were found for the fatty acids. From these results, it was concluded that large differences in surface area per molecule of two components must be important for the new phase formation in heteromultilayers.
\end{abstract}

KEY WORDS Hetero-Structured Multilayer / Amphiphilic Diacetylene Compound / Fatty Acid / New Phase Formation /

Recently fabrication of polar LangmuirBlodgett (LB) films ${ }^{1,2}$ has been investigated with particular references to their physical properties such as piezoelectricity, pyroelectricity ${ }^{3}$ and even-order nonlinear optical effects. ${ }^{4}$ In previous paper we studied the alternately deposited multilayers of amphiphilic diacetylenes $\left(\mathrm{CH}_{3}\left(\mathrm{CH}_{2}\right)_{m-1} \mathrm{C} \equiv \mathrm{C}-\mathrm{C} \equiv\right.$ $\left.\mathrm{C}\left(\mathrm{CH}_{2}\right)_{n} \mathrm{CO}_{2} \mathrm{H}: m-n \mathrm{ADA}\right)$ and arachidic acid $\left(\mathrm{CH}_{3}\left(\mathrm{CH}_{2}\right)_{n-2} \mathrm{CO}_{2} \mathrm{H}: \mathrm{C}_{n} \mathrm{CA}, \quad n=20\right)$, and found that in the case of tricosa-2,4diynoic acid (18-0ADA) in which a diacetylene group is conjugated with a carboxyl group, the structure and photopolymerization behavior of 18-0ADA in such alternately deposited multilayers were different from those of multilayer of pure 18-0ADA. ${ }^{5}$ To clarify the reason for this new phase formation, four different types of multilayers with different interlayer interaction between monolayers were prepared by changing the deposition-order, and structural differences of these multilayers were investigated by $\mathrm{X}$ ray diffraction. In addition hetero-structured multilayers of fatty acids which have alkyl groups of different chain lengths were also prepared, and the possibility of new phase formation was investigated.

\section{EXPERIMENTAL}

Fatty acids used were purchased from Tokyo Kasei Co. 18-0ADA was synthesized according to the methods described in the literature. ${ }^{6}$ It was purified by column chromatography (silica gel, benzene) and recrystallized twice from hexane-ether mixture in the dark place. Chloroform of spectroscopic 
quality was used as a solvent for spreading. Water as a subphase was distilled twice.

A commercially available film balance (MGW Lauda) was used as a trouph. Monolayers were spread from chloroform solution $\left(c a .1 \times 10^{-3} \mathrm{M}\right)$ onto $1 \times 10^{-3} \mathrm{M} \mathrm{CdCl}_{2}$ aqueous solution $\left(\mathrm{pH} \mathrm{5.8)}\right.$ at $20^{\circ} \mathrm{C}$. They were transferred onto quartz plates by the LB technique under a surface pressure of $20 \mathrm{mN} \mathrm{m}^{-1}$.
The lifting and dipping rates were 4 and $6 \mathrm{~mm} \mathrm{~min}^{-1}$, respectively. The first layer was always deposited during the upward stroke because of the hydrophilic surface of the quartz substrate. To provide four different types of interlayer interactions, monolayers were deposited in the orders shown in Figure 1(1)-(4).

Photopolymerization of the diacetylene in
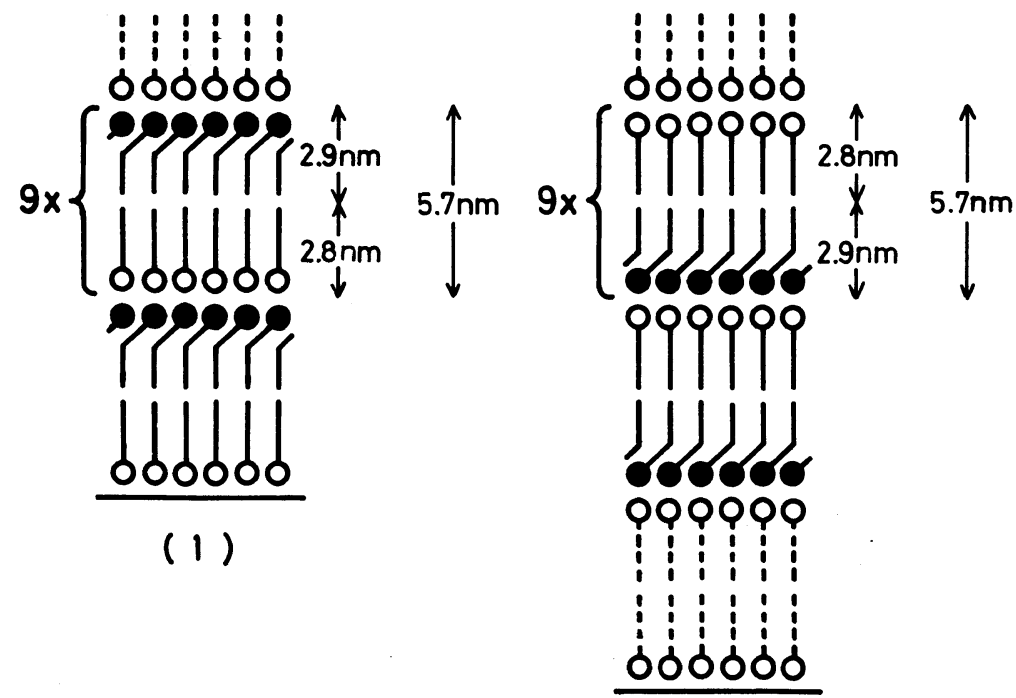

(2)

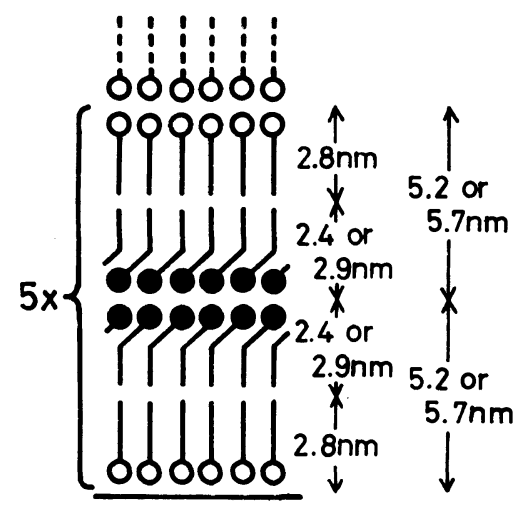

(3)

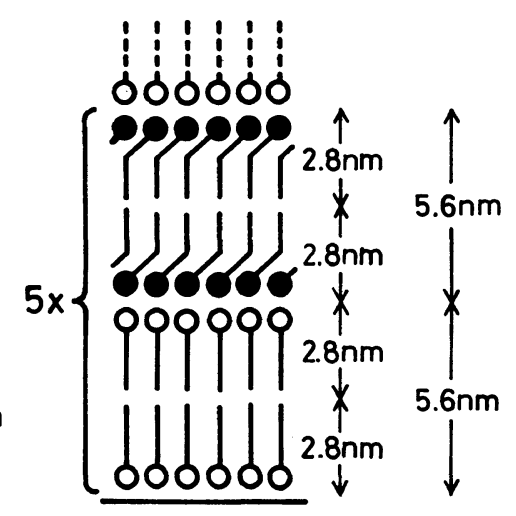

(4)

$$
\oint i: c_{20} C A \quad J: 18-0 A D A
$$

Figure 1. Structural models of multilayers composed of $\mathrm{C}_{20} \mathrm{CA}$ and 18-0ADA. 
multilayers was stimulated by UV irradiation. In the experiment on a change of visible spectra, multilayers were irradiated by an $8 \mathrm{~W}$ UV lamp (Tokyo Kagaku Kikai K. K., PUV1A) at a distance of $2 \mathrm{~cm}$. For the measurement of interlayer spacings of polymers, multilayers were irradiated by a $400 \mathrm{~W}$ mercury lamp (Toshiba, H-400P) at a distance of $30 \mathrm{~cm}$ for $10 \mathrm{~min}$.

Visible spectra of multilayers were measured by a Shimadzu UV-220. X-ray diffraction patterns were recorded on a powder diffractometer (Rigaku Denki, 2035) using Ni-filtered $\mathrm{Cu}-K_{\alpha}$ radiation. Interlayer spacings were calculated from the $2 \theta$ values of a progression of reflections, and were averaged.

\section{RESULTS AND DISCUSSION}

From the point of view of interlayer interactions between 18-0ADA and $\mathrm{C}_{20} \mathrm{CA}$, single layer of 18-0ADA is sandwiched with $\mathrm{C}_{20} \mathrm{CA}$ layers in the multilayers (1) and (2) in Figure 1 and therefore has both hydrophobic and hydrophilic contact between 18-0ADA and $\mathrm{C}_{20} \mathrm{CA}$. The only difference between (1) and (2) is the process of deposition: in (1), 180ADA started to have interaction with $\mathrm{C}_{20} \mathrm{CA}$ at the hydrophobic ends, whereas in (2) at the hydrophilic ends. 18-0ADA in (3) and (4) has its own interactions, say between hydrophilic ends in (3) and between hydrophobic ends in (4), in addition to those with $\mathrm{C}_{20} \mathrm{CA}$.

Table I summarizes the interlayer spacing data of monomers and polymers of the four structures in Figure 1. For comparison, those of the pure $\mathrm{C}_{20} \mathrm{CA}$ and 18-0ADA are also given. In the case of the multilayers (1) and (2) where 18-0ADA monolayers were placed between $\mathrm{C}_{20} \mathrm{CA}$ monolayers, a single interlayer spacing of about $5.7 \mathrm{~nm}$ was observed. When the contribution of $\mathrm{C}_{20} \mathrm{CA}(2.76 \mathrm{~nm})$ is substracted from the spacing, based on the assumption that $\mathrm{C}_{20} \mathrm{CA}$ stays in the same arrangement as in its pure multilayers, one can obtain 2.90 and $2.99 \mathrm{~nm}$ as the contribution of
Table I. Interlayer spacings of multilayers composed of $\mathrm{C}_{20} \mathrm{CA}$ and 18-0ADA (both Cd salts) ${ }^{\mathrm{a}}$

\begin{tabular}{clc}
\hline \multirow{2}{*}{ Multilayer } & \multicolumn{2}{c}{ Interlayer spacing/nm } \\
\cline { 2 - 3 } & Monomer & Polymer \\
\hline \multirow{2}{*}{$\mathrm{C}_{20} \mathrm{CA}$} & 5.51 & - \\
18-0ADA & 4.73 & 5.42 \\
$(1)$ & 5.66 & 5.56 \\
$(2)$ & 5.75 & 5.58 \\
$(3)$ & $5.18(5.66)$ & $5.46^{*}$ \\
$(4)$ & $5.58^{*}$ & $5.51^{*}$ \\
\hline
\end{tabular}

a Asterisks indicate that other weak diffraction peaks exist.

18-0ADA in (1) and (2), respectively. These are far larger than the half-spacings of pure 18-0ADA multilayers $(2.37 \mathrm{~nm})$, and are clear indication of new phase formation of 18-0ADA in (1) and (2).

On the other hand, in the multilayer (3) interlayer spacings of $5.66 \mathrm{~nm}$ were observed as minor fractions, judging from the intensities of diffraction, besides the main spacings of $5.18 \mathrm{~nm}$. The latter spacings almost coincide with the sum of the half-spacings of the pure $\mathrm{C}_{20} \mathrm{CA}$ and 18-0ADA, i.e., $5.12 \mathrm{~nm}$, whereas the former are close to those of the multilayer (1) and (2). It seems that the same phase of 18$0 A D A$ as that in the pure multilayer is predominant.

In the case of (4), it was expected that completely new interlayer spacings, i.e., the sum of those of 18-0ADA $(4.73 \mathrm{~nm})$ and $\mathrm{C}_{20} \mathrm{CA}(5.51 \mathrm{~nm})$, might appear. However, major diffractions corresponded to the same spacings as those of (1) and (2).

One of the most plausible explanations for these results that the new phase appears in (1), (2) and (4) and the original one in (3), is as follows. In the multilayers (1), (2) and (4), carboxylic ends of 18-0ADA interact with carboxylic ends of $\mathrm{C}_{20} \mathrm{CA}$, through cadmium ions. Since these bridgings are strong, 180ADAs with bigger surface area per molecule $\left(0.28 \mathrm{~nm}^{2}\right)$ in their pure monolayer are forced to reduce their surface area, near to that of 


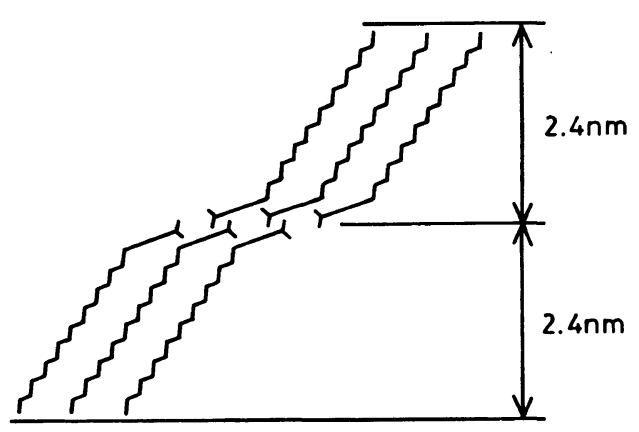

(a)

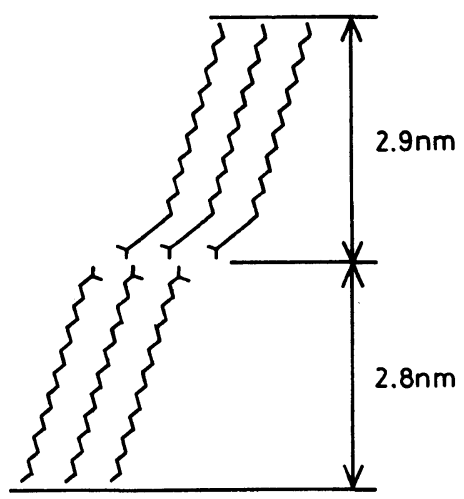

(b)

Figure 2. Considerable molecular arrangements of bilayers in multilayers. (a) pure 18-0ADA. (b) alternating deposition of $\mathrm{C}_{20} \mathrm{CA}$ and 18-0ADA.

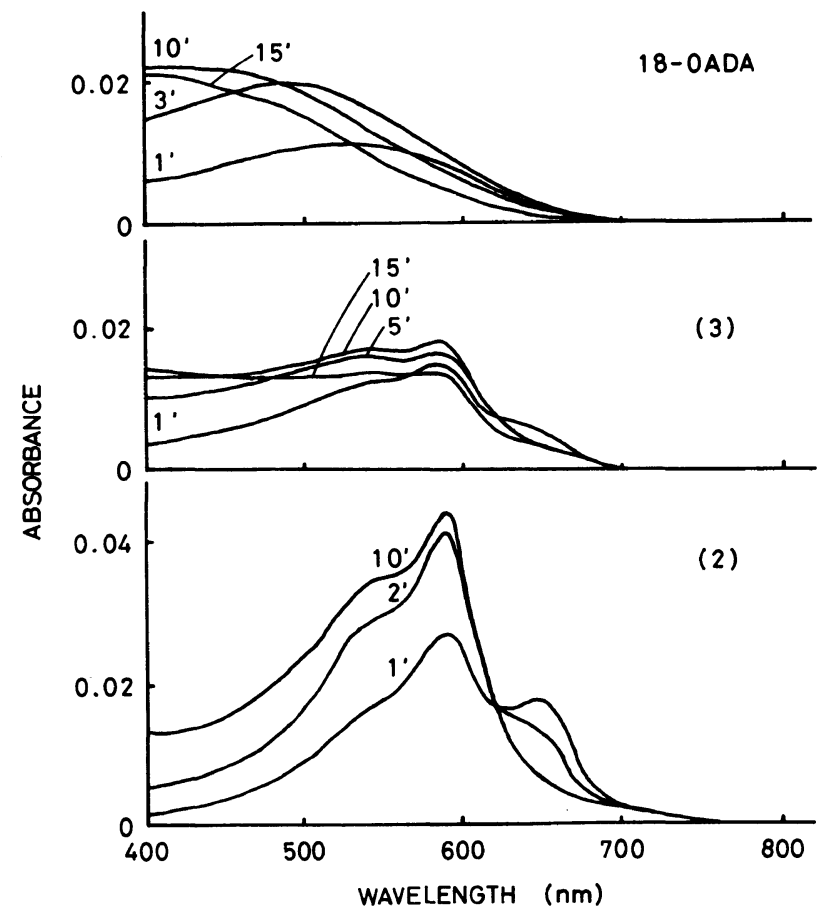

Figure 3. Absorption spectra of multilayers with changing UV-irradiation time. See Figure 1 for the structures of (3) and (2).

$\mathrm{C}_{20} \mathrm{CA}\left(0.20 \mathrm{~nm}^{2}\right)$ with stronger intermolecular interactions, and this reduction of surface area causes the new phase of 18-0ADA in such a way that 18-0ADAs stands up more with respect to the substrate, resulting in more contribution to the interlayer spacing (Figure 2). On the contrary, in the multilayer (3), the carboxylic ends of 18-0ADAs make bridgings by themselves to form their own structures. It is likely that ionic or hydrogen-bond interac- 
tions by themselves overcome coulombic interactions with $\mathrm{C}_{20} \mathrm{CAs}$.

The polymerization behavior of 18-0ADA in these four multilayers well reflects the structural differences mentioned above. The multilayers of (1) and (2) became blue colored polymers on irradiation of UV light. Their polymerization behavior clearly differed from that of pure multilayers of 18-0ADA, which gave only orange colored polymers. The multilayer (3) showed an intermediate polymerization behavior of (1) and /or (2), and the pure 18-0ADA (Figure 3), indicating the coexistence of new and original phases. In the case of the multilayer (4), more complicated color change, i.e., intermediate of (2) and (3), was observed. This suggests the coexistense of small amounts of original phase. In fact, in the $\mathrm{X}$-ray diffraction, several weak and unidentified peaks were observed.

To confirm the above-mentioned assumption that interlayer interactions between carboxylic ends of molecules with different surface areas play crucial roles in the formation of new phase, the same types of heteromultilayers of two fatty acids having different molecular lengths but the same surface area, i.e., stearic acid $\left(\mathrm{C}_{18} \mathrm{CA}\right)$ and behenic acid $\left(\mathrm{C}_{22} \mathrm{CA}\right)$, were prepared, and the structures were examined by X-ray diffraction. ${ }^{7}$ The orders of deposition and interlayer spacings are shown in Table II.

The multilayers (1)-(3) gave exactly the averaged spacing of those of the pure components, and (4) exactly the summed-up spacings of the two components. In the case of (4) only reflections with even-numbered indices were observed. From these results, it is obvious that in all four multilayers (1)-(4), the two fatty acids keep the same molecular arrangements as those in the pure multilayers. In fact, even in the case of diacetylenes, 14-8ADA whose surface area per molecule $\left(0.23 \mathrm{~nm}^{2}\right)$ is close to that of $\mathrm{C}_{20} \mathrm{CA}$ did not form any new
Table II. Interlayer spacings of multilayers composed of $\mathrm{C}_{18} \mathrm{CA}$ and $\mathrm{C}_{22} \mathrm{CA}$ (both $\mathrm{Cd}$ salts)

\begin{tabular}{ccc} 
Multilayers & & $\begin{array}{c}\text { Interlayer } \\
\text { spacing (nm) }\end{array}$ \\
\hline & $\mathrm{C}_{18} \mathrm{CA}$ & 5.03 \\
& $(1)$ & 5.57 \\
& $(2)$ & 5.55 \\
& $(3)$ & 5.55 \\
& $(4)$ & 11.1 \\
& $\mathrm{C}_{22} \mathrm{CA}$ & 6.05 \\
\hline
\end{tabular}

phase in the hetero-multilayers 14-8ADA/ $\mathrm{C}_{20} \mathrm{CA}^{5}$

In conclusion, in the case of the compounds with different surface area per molecule like 18-0ADA and $\mathrm{C}_{20} \mathrm{CA}$, there is the fair possibility of new phase formation in their heterostructured multilayers. But in the case of compounds with similar surface area per molecule like two fatty acids or 14-8ADA and $\mathrm{C}_{20} \mathrm{CA}$, they show only original phases even in their hetero-multilayers. Monolayers with stronger and more perfect molecular arrangements could be used as substrates for the control of structure, properties and/or reactivities of another monolayers in hetero-structured multilayers.

\section{REFERENCES}

1. L. M. Blinov, N. V. Dubinin, L. V. Mikhnev, and S. G. Yudin, Thin Solid Films, 120, 161 (1984).

2. M. F. Daniel and G. W. Smith, Mol. Cryst. Liq. Cryst., 102, 193 (1984).

3. G. W. Smith, M. F. Daniel, J. W. Barton, and N. Ratcliffe, Thin Solid Films, 132, 125 (1985).

4. I. R. Girling, P. V. Kolinsky, N. A. Cade, J. D. Earls, and I. R. Peterson, Opt. Commun., 55, 289 (1985).

5. H. Nakanishi, S. Okada, H. Matsuda, M. Kato, M. Sugi, M. Saito, and S. Iizima, Jpn. J. Appl. Phys., 26, 1622 (1987).

6. B. Tieke, G. Lieser, and G. Wegner, J. Polym. Sci., Polym. Chem. Ed., 17, 1631 (1979).

7. A. Matsuda, M. Sugi, T. Fukui, S. Iizima, M. Miyahara, and Y. Otsubo, J. Appl. Phys., 48, 771 (1977). 